\title{
O INSTITUTO BRASILEIRO DO CAFÉ: UMA HISTÓRIA SOBRE O PATRIMÔNIO INDUSTRIAL
}

\author{
Ana Lívia Périco, Cristina Maria Perissinotto Baron \\ Universidade Estadual Paulista - FCT/UNESP, Presidente Prudente, SP. e-mail: analivia.perico@yahoo.com.br
}

\begin{abstract}
RESUMO
A história da ocupação da região oeste paulista ocorre em função da expansão do sistema ferroviário. Presidente Prudente se consolida, na década de 40, como importante centro de serviços e produção de produtos agropecuários como café, algodão, amendoim, criação de gado e leite. Em 1952, o Governo Federal cria o Instituto Brasileiro do Café - IBC com o intuito de realizar a política econômica do café brasileiro no país e no exterior. O IBC também edificou vários galpões para armazenamento do produto e, em Presidente Prudente, o galpão é instalado nas adjacências da linha férrea, compondo uma paisagem urbana. Este trabalho apresenta a inserção da edificação a partir da história do Município e discute a importância do edifício para a vida da comunidade. Como resultado desta pesquisa espera-se sensibilizar o poder público, fornecendo subsídios para a gestão e o tombamento desta edificação. Apresenta-se uma proposta projetual de um local de eventos.
\end{abstract}

Palavras - chave: Patrimônio Industrial, Instituto Brasileiro do Café, Oeste Paulista.

BRAZILIAN INSTITUTE OF COFFEE: A STORY ABOUT THE INDUSTRIAL HERITAGE

\begin{abstract}
The story of the occupation of western São Paulo occurs due to the expansion of the rail system. Presidente Prudente is consolidated, in the 40s, as an important center of services and production of agricultural products such as coffee, cotton, groundnuts, livestock and milk. In 1952, the Federal Government created the Brazilian Coffee Institute - IBC in order to realize the economic policy of the Brazilian coffee in the country and abroad. The IBC also built several sheds for storage of the product, and Presidente Prudente, the shed is installed adjacent to the railway line, forming an urban landscape. This paper presents the integration of the building from the history of the City and discusses the importance of the building to the community. As a result of this research is expected to sensitize the government providing subsidies for the management and the overturning of this building. We present a proposal projetual a venue
\end{abstract}

Keywords: Industrial Heritage, Brazilian Coffee Institute, West Paulista. 


\section{INTRODUÇÃO}

A região designada atualmente de Oeste Paulista era denominada no século XIX de Vale do Paranapanema ou Sertão do Paranapanema. No início do século XX, os trilhos da Estrada de Ferro Sorocabana - EFS chegam a região, mais precisamente em 1919, onde existiam dois núcleos, a Vila Marcondes e a Vila Goulart. Em 1921, devido ao rápido desenvolvimento, é criado o Município de Presidente Prudente, meses após a inauguração da Estação Ferroviária. Esta teve importante papel na ocupação deste território, pois além de escoar os produtos agrícolas café e algodão, além dos produtos pecuários, foi também responsável por trazer investidores para a região para a compra de terras. Presidente Prudente foi criada pela Lei $\mathrm{n}^{0} 1798$ de 28 de novembro de 1921. (ABREU, 1972)

Nos primeiros anos da sua existência, - Município edificou um importante Patrimônio Industrial e Ferroviário, o qual, na sua maioria, ainda permanece na paisagem urbana, representando um momento da história e da memória da cidade. Como indústrias públicas, para armazenamento ou processamento de produtos agropecuários, identificou-se o Matadouro Municipal (1937), o Armazém do Expurgo (1942), os galpões da antiga FEPASA (década de 40) e o Instituto Brasileiro do Café - IBC (década de 50). Os galpões da FEPASA fazem parte de um conjunto urbano formado pela Estação Ferroviária e Vilas Ferroviárias. As indústrias privadas instaladas foram: Continental Gin Co (1935); Anderson Clayton \& Cia Ltda (1937); S.A. Indústrias Reunidas Francisco Matarazzo (1937); Sociedade Algodoeira do Nordeste Brasileiro - SANBRA (década de 40); Curtume Crespoli (1944); Bebidas Wilson (1945); Bebidas Funada (1947); Asteca (1948) e Sakura (1950). (BARON et al., 2011; HIRAO, 2011)

Este trabalho é resultante de estudos realizados para a implantação de um Centro de Eventos em Presidente Prudente, o qual apresentou como vocação para a área de implantação o Galpão do Instituto Brasileiro de Café, edificado na década de 50. Ao depararmos com tal edificação, presente no cotidiano e no imaginário da população, no deparamos com questões sobre refuncionalização e preservação do patrimônio histórico e cultural. Apresenta-se, portanto, as justificativas para propor novos usos ao Galpão, a história do IBC e o projeto proposto para compor o programa, trabalhando o projeto como uma proposta de pesquisa para refuncionaização do antigo galpão, lembrando que o mesmo não é tombado ${ }^{1}$.

\footnotetext{
${ }^{1}$ Este trabalho foi desenvolvido originalmente como Trabalho Final de Graduação, apresentado ao Curso de arquitetura e Urbanismo, da Faculdade de Ciências e Tecnologia - Universidade Estadual Paulista "Júlio de Mesquita Filho" - Campus Presidente Prudente. (PÉRICO, 2010)
} 
UMA PROPOSTA DE REFUNCIONALIZAÇÃO CENTRO DE EVENTOS

Ao propor um local para eventos no Instituto Brasileiro do Café, realizou-se uma pesquisa para verificar a viabilidade e qual o papel que este desempenharia para 0 Município de Presidente Prudente. Este local já havia funcionando como um importante equipamento do complexo industrial e a intenção era voltar a colocá-lo para uso da população, refuncionalizado e reestruturado para atender as novas demandas. Partindo da evolução do Setor Terciário da economia ao longo dos séculos, pode-se dizer que os espaços terciários, que inicialmente tinham por objetivo o encontro de pessoas para a realização da troca de bens e serviços visando à satisfação de ambos os envolvidos, passaram a se basear, sobretudo, no lucro neles gerados, sendo necessário, portanto, uma análise da área a ser implantado o estabelecimento observando desde a acessibilidade, presença de público consumidor até mesmo a presença de segurança, crescimento e satisfação pessoal ali presentes.

Ao longo do século XX as Exposições Universais, hoje chamadas de Internacionais, perderam sua importância como evento catalisador e divulgador de novos produtos, bem como o poder de sedução perante 0 público para as Exposições Industriais, as quais passaram a focar um tipo de produto, serviço ou ramo de atividade, iniciando um ciclo de expansão e segmentação que permanece até os dias atuais. Outro tipo de atividade incorporada foi a de compra e venda, originando as Feiras de Comércio ou de Negócios as quais passaram a utilizar somente o espaço coberto dos pavilhões e, em alguns casos, promoveram a construção ou a expansão de anexos aos pavilhões, objetivando espaços para Exposições Universais. Estes anexos possibilitaram a comunicação e interligação entre si, permitindo a existência de mais de um evento simultâneo no conjunto de pavilhões, agora denominado Centro de Exposições, caracterizados por espaços mais amplos, com alto desenvolvimento tecnológico, com um mínimo ou total ausência de colunas no meio do pavilhão, possibilitando maior flexibilidade no desenho das feiras. (CARVALHO, 2009, p.35, 36)

Por meio do aprimoramento técnico das feiras e exposições, surgem eventos voltados principalmente para um público técnico especializado no assunto: Congressos e Convenções. Surgiram, assim, espaços anexos para abarcar essa nova demanda - os auditórios e salas de conferencias formando o então denominado Centro de Convenções. (CARVALHO, 2009, p.36)

O setor terciário abriga, atualmente, uma ampla diferenciação das atividades incluindo comércio atacadista, comércio 
varejista, alojamento, alimentação, transportes, saúde, educação, apresentando ainda atividades culturais, recreativas entre outras. Entretanto, esse trabalho enfatiza a atividade de eventos presente nesse setor, destacando, sobretudo, suas vantagens socioeconômicas e a ligação direta que esta atividade possui com relação ao desenvolvimento do turismo na cidade $\mathrm{e}$ região em que se apresenta.

O município de Presidente Prudente, localizado no oeste do estado de São Paulo, apresenta uma área de $562 \mathrm{~km}^{2}$ de extensão e possui 207.411 habitantes (FUNDAÇÃO SEADE, 2009). É considerado Sede Regional da 10aㅡ Região Administrativa do Estado - RA, composta por 53 municípios. Presidente Prudente assume o papel de cidade polo da região apresentando infraestrutura satisfatória, tornando-se adequada para receber investimentos de portes diferenciados e atrair consumidores de toda a região, tanto para compras, como para lazer e entretenimento. As principais vias de acesso são a Rodovia Raposo Tavares (SP270), que faz a ligação com a capital - há 560 $\mathrm{Km}$ - e o Mato Grosso do Sul, a Assis Chateaubriand (SP-425), que une a região ao Paraná e às regiões do oeste e norte do Estado de São Paulo, a Comandante João Ribeiro de Barros (SP-294), que faz a ligação de vários municípios da RA com o Rio Paraná e, no sentido oposto, com Bauru e a Rodovia
Marechal Rondon, e a Julio Budiski (SP-501), que une Presidente Prudente à SP-294. (FUNDAÇÃO SEADE, 2009).

Sendo assim, a localização é um fator que viabiliza a criação do Centro de Eventos, pois a cidade está localizada no entroncamento viário de três estados, Mato Grosso do Sul, Minas Gerais e Paraná, além de possibilitar fácil acesso ao Centro-Oeste brasileiro, sendo servida pela ferrovia e pelos Aeroportos de Presidente Prudente, Adamantina e Dracena. Com relação às atividades econômicas, a região que no início tinha como base o produto das lavouras de café, atualmente destaca-se pela expansão da pecuária, chegando até mesmo a ser considerada um dos pólos pecuaristas do estado e maior região exportadora de carne bovina do país, o que confirma a importância do setor agropecuário para o desenvolvimento da cidade, também denominada "Capital Nacional do Nelore e do Cavalo Quarto-de-Milha"²,elevando o contingente ligado ao setor de comércio e serviços. Devido à proximidade com a matéria-prima, há predominância também da agroindústria no setor secundário da cidade com destaque na produção de gêneros alimentícios de origem agrícola, animal, bebidas, vinagre e frigoríficos.

Já no setor terciário, a diversidade do comércio levou a cidade a se tornar um pólo

\footnotetext{
2 Instituto de Economia Agrícola e Coordenadoria de Assistência Técnica Integral - Dados de 2007
} 
atacadista e varejista regional, o qual atende não apenas o estado de São Paulo como também o Paraná e Mato Grosso do Sul. (FUNDAÇÃO SEADE, 2009). Com a evolução do setor agropecuário e a agroindústria, é comum na região, a ocorrência de simpósios, convenções, palestras e até mesmo coquetéis de lançamento de produtos da área, além das feiras e exposições que ocorrem anualmente na cidade.

Outro aspecto de destaque em Presidente Prudente é a presença de duas universidades - Universidade Estadual Paulista "Júlio de Mesquita Filho"- Unesp e Universidade do Oeste Paulista -Unoeste; três Instituições de Ensino Superior - Uniesp, Fatec - Faculdade de Tecnologia e Faculdades Integradas "Antônio Eufrásio de Toledo" - e Intituições de Cursos Técnicos Profissionalizantes - Senai e Senac, que juntas concentram aproximadamente $30 \mathrm{mil}$ alunos provenientes de todas as regiões do Brasil, distribuídos em mais de 150 cursos de graduação, pós-graduação e cursos técnicos ${ }^{3}$. Os eventos consolidados são a Festa das Nações e as festas de cultura japonesa, como Sushi Fest e o Nikkei Fest. O Sushi Fest, realizado pela TV Fronteira, o ocorre durante quatro dias e recebe um público de aproximadamente 50 mil pessoas que podem fazer uso de uma ampla praça de alimentação, além de visitarem exposições,

\footnotetext{
${ }^{3}$ Dados referentes ao ano de 2009, coletados através de contatos com a seção de graduação/secretaria de cada instituição citada.
}

participar de workshops, shows entre outras atrações. O Nikkei Fest - realizado pela Associação Cultural, Agrícola e Esportiva de Presidente Prudente (ACAE), em parceria com demais entidades nikkeis da cidade. Esta festa, assim como o Sushi Fest, também conta com uma infraestrutura capaz de suportar uma praça de alimentação com comidas típicas, atrações culturais, workshops, exposições, artesanatos e shows de música e dança.

A dinâmica socioeconômica do município apresenta possibilidades para a execução de um Centro de Eventos e, ao procurar possibilidades para implantação de um empreendimento deste porte foi natural que a área e a própria edificação do Instituto Brasileiro do Café se mostrasse compatível para tal empreitada, como veremos a seguir.

\section{RESULTADOS}

\section{O local de intervenção}

A escolha da área para implantação do equipamento proposto foi fundamentada em estudos de caso realizados em Centros de Eventos presentes em cidades médias; visitas a espaços existentes em Presidente Prudente, os quais costumam receber as atividades e o público alvo enfocados nesse projeto, bem como a carência de espaços com as devidas infraestruturas para comportar a demanda da cidade. Além desses pontos foram levados em 
consideração diretrizes básicas como adequação à legislação; forma de aquisição; padrão de ocupação atual ou recente da área; acessos e acessibilidade; tamanho e forma e topografia, as quais deram suporte para o programa e, consequentemente, resultou em uma área que comportasse 0 tipo de espaço em questão.

Dessa forma, ao longo dos estudos até então realizados, a área do antigo Instituto Brasileiro de Café de Presidente Prudente - IBC, atual Centro Municipal de Eventos, localizado na Vila Furquim, zona Leste da cidade, apresentou interessantes características a serem levadas em conta, pois, embora considerado um centro de eventos, o espaço o qual atualmente recebeu melhorias municipais ainda encontra-se ausente de uma infraestrutura adequada, sendo necessária a cada evento realizado, a montagem de uma infraestrutura móvel que possa atender ao público ali presente de uma maneira segura e confortável.

$A$ área escolhida também faz parte de um projeto da Secretaria Municipal de Cultura e Turismo para a implementação de um Corredor Histórico em Presidente Prudente, incluindo edificações do quadrilátero central, partindo do entendimento que a paisagem cultural dos primeiros períodos da cidade devem ser preservados para que as gerações futuras compreendam, a partir da história viva, as suas origens e que estas fazem parte da memória coletiva. O Corredor Histórico compreende edificações históricas do centro, o complexo da ferrovia, originalmente, a Estrada de Ferro Sorocabana - EFS, formado pela Estação Ferroviária (atual Fundação de Proteção e Defesa do Consumidor ${ }^{4}$ PROCON), moradias dos trabalhadores e galpões da EFS, como também o patrimônio industrial das Indústrias Reunidas Francisco Matarazzo, de 1937, (atual Centro Cultural Matarazzo), galpão do Instituto Brasileiro do Café e Sociedade Algodoeira do Nordeste Brasileiro - SANBRA (1948). (DUARTE DA SILVA, 2011)

A seguir, na figura 01, é possível compreender a implantação do Corredor Histórico e visualizar uma imagem do IBC na década de 50, quando foi construído e, na sequencia, figura 02, á área onde se localiza o IBC com o seu respectivo entorno.

\footnotetext{
${ }^{4}$ Lei ${ }^{0}$ 9.192, de 23 de novembro de 1995, que institui o PROCON no Estado de São Paulo, vinculado à Secretaria de Estado da Justiça e da Defesa da Cidadania.
} 


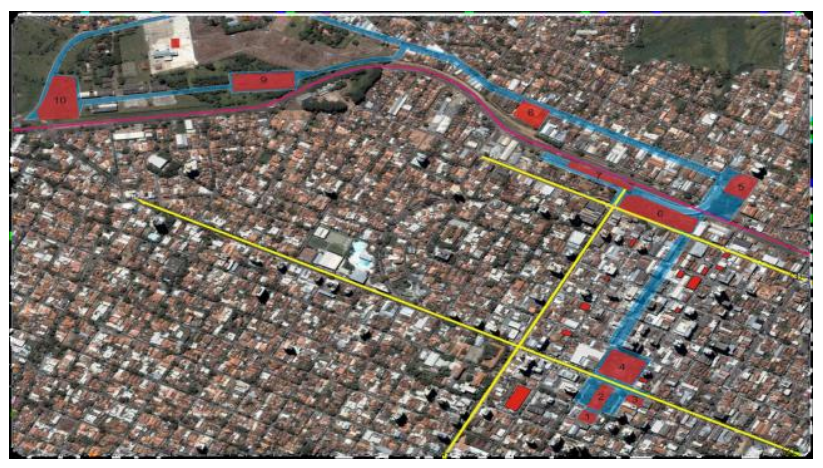

a

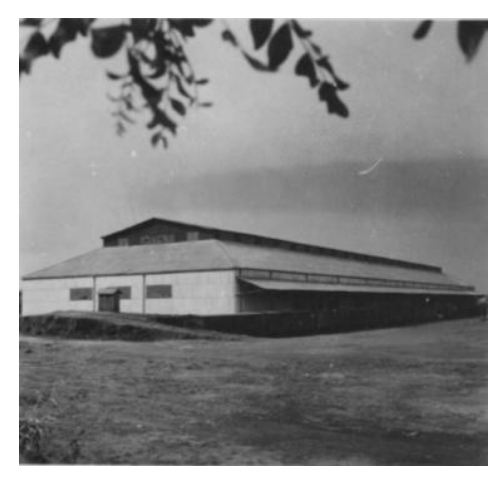

b

Figura 01. Corredor Histórico (a) e Foto do IBC na década de 50 (b).

Fontes: Corredor Histórico - autor desconhecido e Acervo CATI - Presidente Prudente
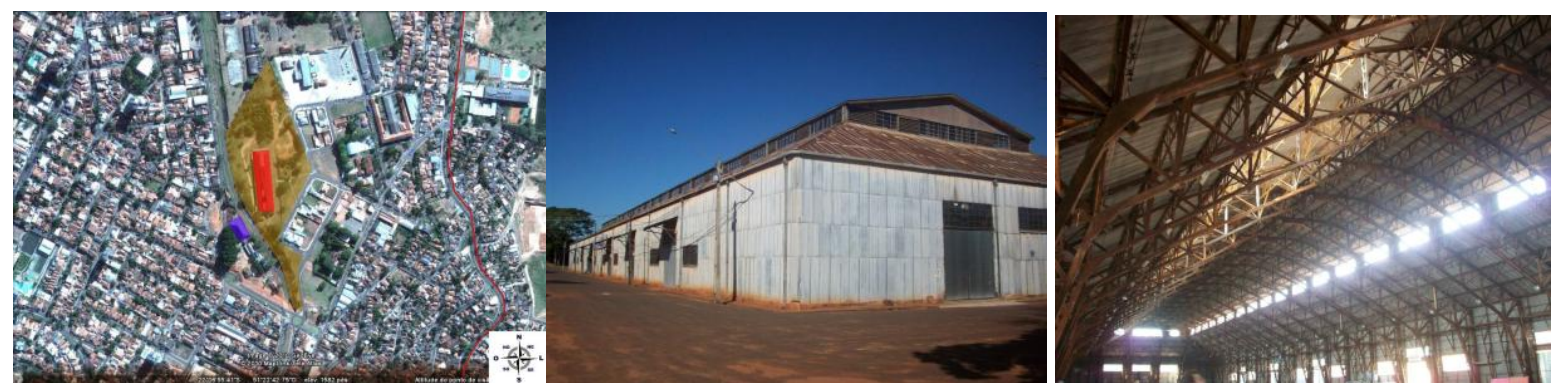

a

b

Figura 02. área de intervenção - vista aérea (a) e fotos do IBC em 2010.

Fonte: PÉRICO (2010).

A história da ferrovia se entrelaça com a história da criação do município e da expansão cafeeira. Segundo Abreu (1972), a Estrada de Ferro Sorocabana teve como fundador Luiz Matheus Maylasky, o qual buscava o escoamento de ferro da fábrica de São João do Ipanema para abastecer São Paulo e os mercados estrangeiros, construída pela Companhia Sorocabana. Este primeiro trecho partia de São João do Ipanema até São Paulo, passando por Sorocaba e São Roque, tendo sido terminado em 1876.

Devido à expansão do café e à criação de gado, os interesses da Sorocabana se expandiram para região de Tietê, Tatuí e
Botucatú, esta última em 1889. A Companhia Ituana (criada em 1873), responsável pelos trechos de Itu a Jundiaí e Itu a Mairinque, para transporte de café, também tinha interesses nesta região. Em 1892 houve a fusão das duas Companhias, recebendo o nome de Companhia União Sorocabana e Ituana, conectando as regiões de Sorocaba, Itu, Jundiaí, Campinas, Piracicaba e Botucatu. Em 1904, a Companhia passa para o Governo Federal em função de problemas financeiros e, em 1905, este transfere para o Governo do Estado de São Paulo, que recorreu a empréstimo no Dresdner Bank de Berlim para sua compra e melhorias. Em 1907, o 
Governo do Estado arrendou a Sorocabana a um sindicato franco-norte-americano, sendo denominada de Railway Company Limited e em agosto de 1919 volta ao Governo do Estado. (ABREU, 1972)

A Sorocabana se expande para 0 Oeste Paulista e em 1917 a ferrovia chega a Indiana, passando por Laranja Doce e Martinópolis; em 1919 chega a Regente Feijó, Presidente Prudente e Presidente Bernardes; em 1920 a Santo Anastácio; em 1921 a Presidente Venceslau e em 1922 a Presidente Epitácio, última estação inaugurada em primeiro de maio de 1922 . A inauguração da Estação de Presidente Prudente contou com a participação do então Presidente de Estado Washington Luís em 14 de outubro de 1921. (ABREU, 1972)

O município teve na década de 1920, a cultura cafeeira como atividade econômica mais importante, exercida por proprietários de terras, empreiteiras e colonos. O sucesso da monocultura cafeeira e seu apogeu nas novas áreas de plantio do Oeste Paulista trouxe colonos, principalmente de Minas Gerais e, promoveu o povoamento das novas cidades. Destaca-se também a produção do algodão, substituindo o café.

Após um período de prosperidade e enriquecimento de produtores e das novas cidades surgidas com o café, o produto, principal item da pauta de exportações do país, entrou em declínio após a crise econômica de 1929 que limitou importações, principalmente dos EUA, promovendo a queda de preços e acúmulo de produto sem ter para onde ser escoado. Com isso, houve a queima de estoques para sua valorização, mas o impasse continuou, sofrendo o café inúmeras desvalorizações ao longo das décadas de 1940 e início da década de 1950.

Como política de valorização do café, o Governo do Estado de São Paulo criou, em 1924, o Instituto Paulista de Defesa Permanente do Café que, em 1926, passou a denominar-se Instituto de Café do Estado de São Paulo ${ }^{5}$. (PELÁEZ, 1973). No período de 1929 a 1933, período de crise, o Conselho Nacional do Café - CNC, entidade federal criada em 1931, assume as atribuições de defesa do café brasileiro. Quando o CNC foi extinto, em 1933, tem-se a criação do Departamento Nacional do Café ${ }^{6}$ - DNC e em 1952, cria-se o Instituto Brasileiro do Café (IBC), criado através da Lei N. 1779, de 22 de dezembro de 1952, incorporando mais uma vez as atividades, bem como o patrimônio do então extinto Departamento Nacional do Café, extinto ${ }^{7}$ em 1946.

O IBC tinha como objetivo a política econômica do café brasileiro no país e no exterior. Para realizar essa política, o IBC iniciou uma série de posturas, tais como promoção de pesquisas e experimentação

\footnotetext{
${ }^{5}$ Leis $n^{0} 2004$, de 19 de dezembro de 1924 e Decreto $n^{0} 4.301$ de 22 de março de 1926. São Paulo.

${ }^{6}$ Decreto ${ }^{0} 22.452$, de 10 de fevereiro de 1933.

${ }^{7}$ Decreto-LEI № 9.068, DE 15 DE MARÇO DE 1946.
} 
em agricultura e tecnologia cafeeira, para baratear custos, aumentar a produção e melhorar a qualidade com o fim de exportação. O IBC também promoveu a defesa de preço justo para o produtor, levando em conta a concorrência externa e incentivando o consumo do café brasileiro, aliando a isso uma comercialização aperfeiçoada, facilitando o escoamento do produto e promovendo maior publicidade no exterior.

O IBC atuou até finais da década de 1980 do século XX, sendo extinto em 1990, tendo sua função e atribuições transferidas para o Ministério do Planejamento, em novembro de $1991^{8}$. Seu patrimônio foi incorporado ao Ministério do Planejamento que passou a ser o mantenedor dessas diversas edificações, espalhadas por todo país, até o presente. Os antigos imóveis, em sua maioria galpões de armazenamento, perderam sua função ou foram subutilizados por outros órgãos da administração federal, ou simplesmente abandonados, entrando em processo de decadência, sem qualquer manutenção ou processo de recuperação. Com Isso foram surgindo em todo país soluções de ocupação dos antigos galpões, criando projetos de resgate do patrimônio histórico e sua importância para as cidades onde essas edificações, anteriormente ativas, perderam sua função para a comunidade.

\footnotetext{
${ }^{8}$ Lei $n^{0} 8.029$, de 12 de abril de 1990 e Decreto $n^{0} 99.240$, de 7 de maio de 1990.
}

A exemplo disso, pode-se citar o caso de Presidente Prudente, onde após anos de abandono e subutilização do antigo galpão do IBC, a Prefeitura Municipal entrou em negociação junto ao Ministério do Planejamento, responsável pelo imóvel localizado na Vila Furquim, com o objetivo de ocupar, recuperar e utilizar com novos fins a edificação. Depois de entendimentos, por meio de um contrato firmado em abril de 2007, coube a Prefeitura Municipal de Presidente Prudente por um período de vinte anos, a utilização do antigo galpão, com $4.900 \mathrm{~m}^{2}$ de área construída, juntamente com a área de entorno que atinge $36.300 \mathrm{~m}^{2}$, para a instalação do Centro Municipal de Eventos.

Dessa maneira, o antigo galpão do IBC em Presidente Prudente entra em processo de recuperação e, apesar de ainda não apresentar uma infraestrutura adequada, vem sendo utilizado para festas, quermesses, exposições, entre outros eventos recuperando assim, a vida e a utilidade de um espaço já conhecido e valorizado pela comunidade. Isso possibilitou a recuperação do entorno e sua inclusão na vida cultural da cidade, promovendo juntamente com o Centro Cultural Matarazzo, o desenvolvimento de uma região histórica até então estagnada.

Portanto, ao buscar um espaço adequado para a realização do Centro de Eventos e ao deparar-se com o local do IBC, 
além de possuir os requisitos necessários ao programa proposto, percebeu-se a grande importância de valorizar esta edificação como bem cultural, devido a sua história como também a sua arquitetura.

\section{O projeto}

Após realizar análises e estudos aprofundados com relação ao tema e a área a ser trabalhada, o projeto arquitetônico proposto considerou a importância do galpão do IBC, mesmo não sendo um bem tombado, propondo intervenções para valorizar a sua inserção na malha urbana, bem como, garantir a sua permanência na paisagem urbana.

Dessa forma, o programa está fundamentado em incorporar o "barracão" já existente aos novos espaços projetados, possibilitando além da requalificação do antigo pavilhão, a criação das grandes áreas implantadas em anexo ao mesmo, utilizando de sua própria área de entorno. 0 projeto foi estruturado de maneira a enfatizar uma arquitetura de contraste, porém, de forma equilibrada, utilizando-se de materiais antigos e também contemporâneos, de modo que o primeiro faça perdurar a tradição e a história ali presente, enquanto o segundo remete a uma ideia de praticidade, proporcionando a criação de ambientes moduláveis, seguros e dotados de infraestrutura, possíveis de comportar variados tipos de eventos que podem ocorrer de modo individual ou concomitantemente permitindo, ainda, a integração entre os espaços.

Assim, o espaço enfatizará a integração entre o "antigo e o novo" através de um partido que faça "conversar" o patrimônio cultural com uma edificação contemporânea. Desta maneira, como resultado, o projeto tem por base conceber em um ambiente apto a receber eventos tanto de cunho cultural e acadêmico - feiras, exposições, mostras, vernissage, congressos, conferências, simpósios - como encontros de convivência, cerimônias e lançamentos coquetéis, almoços, jantares, casamentos, cerimônias acadêmicas, lançamentos de livros, serviços e produtos em geral, além dos já citados eventos consolidados da cidade como o caso do Nikkei Fest, Sushi Fest, quermesses, Festa Junina entre outros, os quais utilizariam da área do galpão já existente dotado por sua vez, de uma infraestrutura adequada a esses tipos de eventos.

Esta proposta visa criar um espaço inovador a cidade de Presidente Prudente, utilizando-se de uma área de valor histórico para a população a qual, depois de muito tempo estagnada, vem sendo revitalizada, destacando-se atualmente como uma área de intenso desenvolvimento da cidade. A implantação considerou os estudos 
topográficos, insolação, ventilação, e diagnóstico de uso e ocupação do entorno, buscando melhor entender a intervenção do projeto na paisagem da área a ser trabalhada e, até mesmo um estudo da massa de vegetação existente, obteve-se uma relação entre os dados e o partido adotado para que pudesse ser realizada a implantação dos espaços.

Com relação à topografia, é uma área pouco acidentada, porém, apresenta movimentação de terra em algumas regiões, a qual foi considerada durante a implantação do projeto. Desta maneira, tomando o pavilhão existente como foco específico do projeto, os demais espaços a serem implantados foram posicionados ao seu entorno. O nível no qual se encontra o pavilhão foi adotado como cota base, de forma que tanto o espaço térreo dos salões, onde se encontram o hall de acesso aos mesmos, bem como o espaço semiaberto sob pilotis, localizado abaixo dos salões I e II, e a área de estacionamento localizada abaixo do salão III foram implantados no mesmo nível do pavilhão, permitindo assim uma fácil circulação entre os espaços. (figura 03)

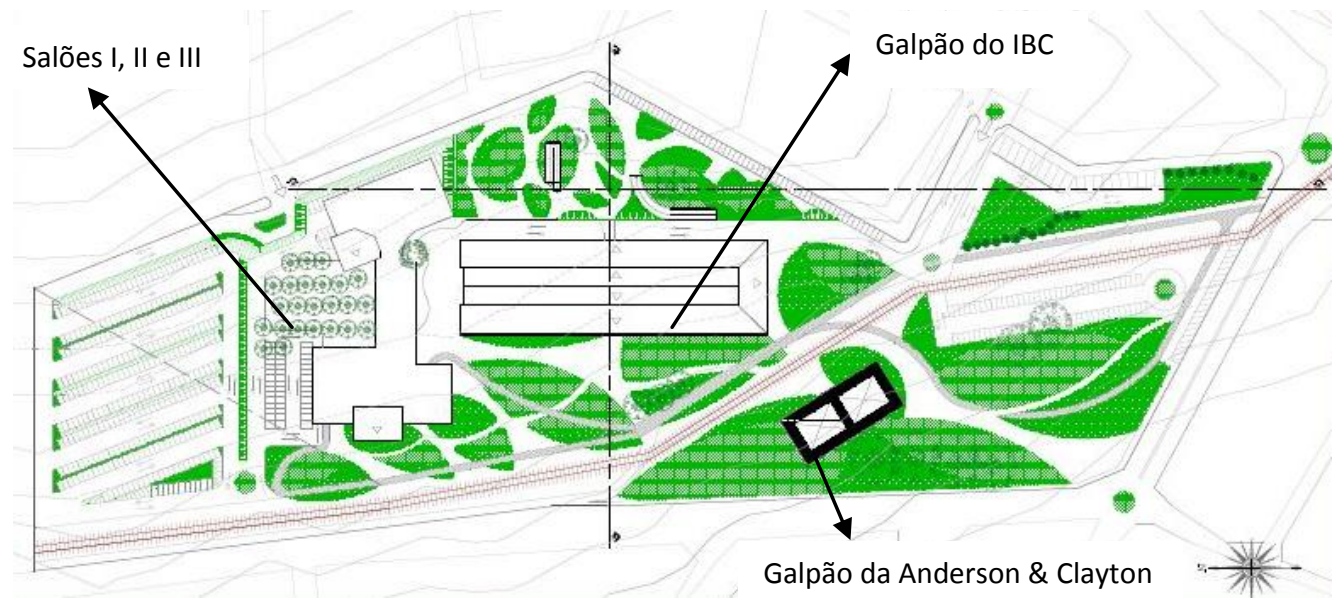

Figura 03. Implantação do Centro de Eventos - IBC

O galpão possui uma área de 4.900 m2, com dimensões de $140 m \times 35 m$ e pé direito de $16 \mathrm{~m}$. Por meio de estudos com relação a sua estrutura, verificou-se que esta é composta por 22 pórticos em madeira, treliçados e cavilhados, distribuídos ao longo de toda a extensão, apresentando um distanciamento de $5.60 \mathrm{~m}$ a cada dois pórticos, sendo esta distância aumentada em suas extremidades, onde encontram-se mais 4 pórticos, que possibilitam o fechamento do mesmo, proporcionando uma forma rígida ao pavilhão e uma cobertura em quatro águas com telhas metálicas presas tem terças treliçadas. Há também a presença de um lanternin, que favorece a iluminação no 
interior do pavilhão. Os pórticos são contraventados por treliças horizontais e verticais, as quais ainda realizam o papel de segurar a vedação de zinco existente.

Após estes levantamentos, optou-se pela preservação de sua estrutura, entretanto, o projeto tem como proposta conservar apenas os pórticos e as terças, sendo implantada uma nova forma de contraventamento, a utilização de aço em perfil cilíndrico de $20 \mathrm{~mm}$. Estes serão dispostos nas laterais, a cada dois pórticos ligando-os através de seu banzo inferior e superior, alternadamente, proporcionando um contraventamento em " $X$ ", o qual também aparecerá em alguns pontos na região da cobertura. Entretanto, tal ligação, nas laterais irá se alternar com o uso de vigas fixadas entre os pórticos a uma altura de 4 metros.

Devido ao fato de ter-se optado pela retirada dos pórticos da extremidade em sua elevação Norte, a fim de proporcionar uma maior visibilidade da estrutura ao observador, os dois últimos pórticos ali existentes, tiveram de ser contraventados de uma forma mais rígida, fazendo uso do perfil em aço e também da viga em madeira nas laterais e ainda realizar um travamento em " $X$ " na cobertura. Estes novos materiais anexados ficarão aparentes, proporcionado a ideia de intervenção no local, onde é possível entender quais são os elementos originais e quais são os novos. Para os novos elementos de madeira propõem-se uma madeira mais clara, também com o intuito de proporcionar que as diferentes épocas se constrastem.

Ainda com relação à estrutura, o pavilhão recebeu uma ampliação dos beirais em ambas as laterais, proporcionando além de uma área de circulação coberta a seus transeuntes, uma maior proteção aos pórticos, pelo fato de serem de madeira e, portanto, apresentarem alguns pontos críticos, caso fiquem desprotegidos. Para isso, foram anexados aos pórticos uma mão francesa em madeira, a qual seguiu o mesmo alinhamento e a estrutura do pórtico. Ao longo de toda extensão da elevação oeste, aproveitou-se da estrutura da mão francesa usando-a como base ao brise em madeira ali anexado, visando uma maior proteção da área.

Baseando-se na ideia de torná-lo, assim como os outros espaços implantados, uma área flexível, o galpão foi subdividido em duas áreas. Em sua região central projetou-se um hall de acesso que tem por finalidade facilitar a circulação do público ali presente. Tal espaço apresenta uma escada de acesso ao mezanino projetado sobre hall o qual se estende para ambos os lados de maneira simétrica, possibilitando uma visão superior aos espaços de exposições.

Com relação à vedação, esta se apresenta em concreto armado aparente, a 
uma altura de $6 \mathrm{~m}$ a partir do nível térreo e está presente ao longo da extensão de todo o pavilhão, entretanto, localiza-se na parte anterior à base dos pórticos, de maneira com que estes passem da área interna para a externa, apresentam-se totalmente visíveis aos seus transeuntes. (figuras 04 e 05)
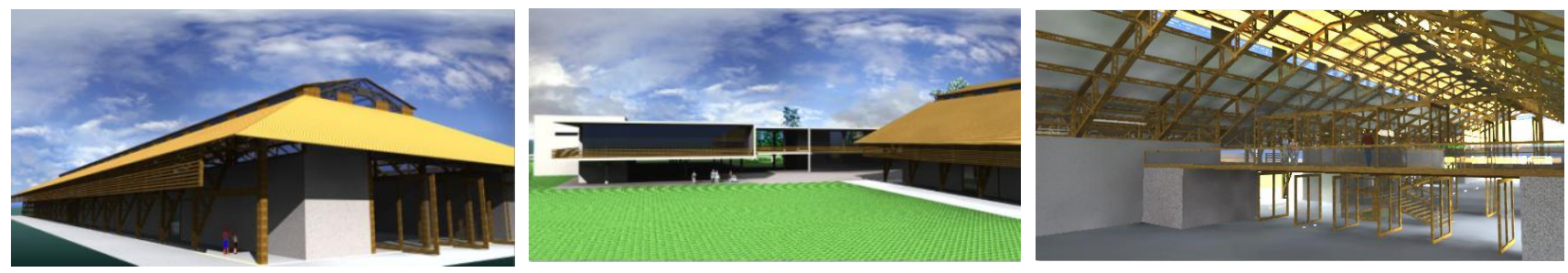

Figura 04. Perspectivas do projeto proposto, vista geral do IBC, vista do complexo e acesso pela passarela.

Fonte: PERICO, 2010.
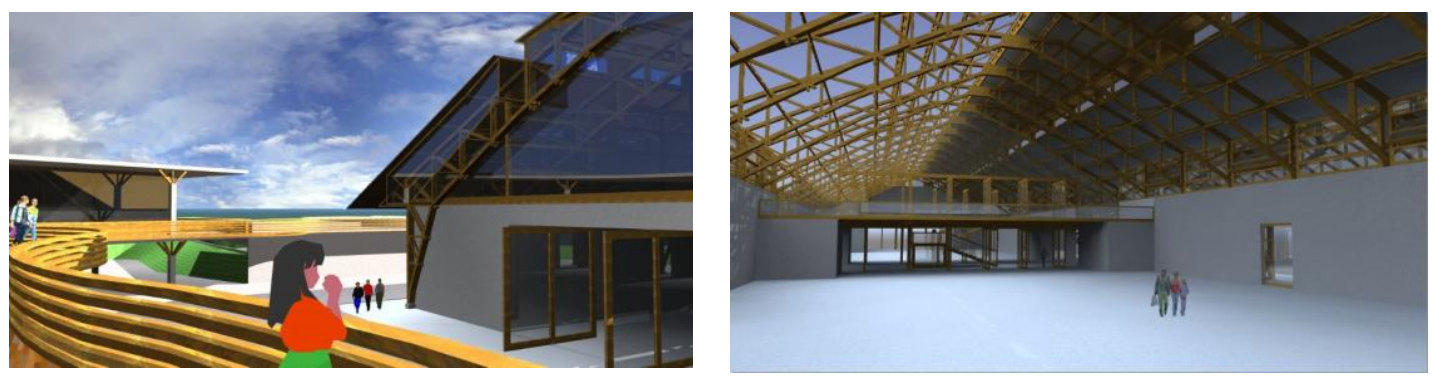

Figura 05. Vista dos anexos para o Galpão do IBC e vista interna

\section{CONSIDERAÇÕES}

O espaço proposto para o Centro de Eventos - IBC, juntamente com o Centro Cultural Matarazzo e o complexo da EFS, poderão se constituir um complexo cultural arquitetônico para a cidade. Dessa forma, um visitante que venha conhecer tais edificações poderá "voltar no tempo" e passear sobre os trilhos, sendo transportados por uma Maria Fumaça a qual saia da própria Estação, passando pelo Centro Cultural Matarazzo indo até o Espaço de Eventos onde ocorrerá uma parada para que a pessoa possa desfrutar do local visitando exposições, feiras ou mesmo a própria área verde ali existente.

Poderá ainda ser integrado ao Corredor Histórico de Presidente Prudente, uma proposta criada pela Secretaria de Cultura e Turismo da cidade, que tem como objetivo preservar e valorizar os patrimônios históricos localizados na trajetória com início na Escola Estadual Adolpho Arruda Mello e término na antiga Sanbra, incluindo espaços como o calçadão, Estação Ferroviária, IRF 
Centro Cultural Matarazzo, Sesi, IBC, entre outros, promovendo a revitalização de espaços públicos e também o crescimento harmônico da cidade, a partir do entendimento que o conjunto compõe uma paisagem cultural, que dever ser preservada.

\section{REFERÊNCIAS}

ABREU, D. S. Formação histórica de uma cidade pioneira paulista: Presidente Prudente: Faculdade de Filosofia, Ciências e Letras de Presidente Prudente, 1972.

BARON, C. M. P. et al. Patrimônio industrial em Presidente Prudente-SP. In: ENCONTRO DE TEORIA DE HISTÓRIA DA ARQUITETURA NO RIO GRANDE DO SUL, 9. Anais... Porto Alegre: UFRGS, 2011.

CARVALHO, K. S. Pavilhões e centros de exposição em São Paulo: cidadelas modernas do mundo globalizado. 2009. $194 \mathrm{f}$. Dissertação (Mestrado) - Faculdade de Arquitetura e Urbanismo da Universidade de São Paulo, São Paulo.

DUARTE DA SILVA, T. R. Requalificação Café Cruzeiro do Sul. 2011. Monografia (Graduação) - Faculdade de Ciências e Tecnologia - Universidade Estadual Paulista "Júlio de Mesquita Filho", Campus de Presidente Prudente - SP.

HIRAO, H. et al. Abandono, descaracterização e demolição do Patrimônio Ferroviário Industrial de Presidente Prudente-SP e a necessidade do inventário histórico e arquitetônico In: SEMINÁRIO IBEROAMERICANO ARQUITETURA E DOCUMENTAÇÃO, 2. Anais... Belo Horizonte: UFMG, 2011.

PELAEZ, C. M. Análise econômica do Programa Brasileiro de Sustentação do Café 1906-1945: Teoria, Política e
Medição. Revista Brasileira de Economia, Rio de Janeiro, v. 25, n. 4, out./dez., 1971.

PERICO, A. L. Espaço de Eventos - IBC. 2010. Monografia (Graduação) - Faculdade de Ciências e Tecnologia - Universidade Estadual Paulista "Júlio de Mesquita Filho", Campus de Presidente Prudente - SP.

Recebido para publicação em 12/08/2014

Revisado em 01/09/2014

Aceito em 06/09/2014 